\title{
Influence of Plastic Deformation on Nanocrystallization of Finemet Alloy
}

\author{
K. $\mathrm{CsACH}^{a}$, J. MišKuF ${ }^{a}$, A. JurÍKOvá ${ }^{a}$ AND G. JANÁK ${ }^{b}$ \\ ${ }^{a}$ Institute of Experimental Physics, Slovak Academy of Sciences, Watsonova 47, 04001 Košice, Slovakia \\ ${ }^{b}$ Department of Materials Science, Metallurgical Faculty, Technical University Košice \\ Letná 9, 04200 Košice, Slovakia
}

\begin{abstract}
The Finemet alloy prepared by the crystallization of an amorphous precursor is a basic model material for study of magnetic nanoparticle structures. Intensive plastic deformation localized in adiabatic shear bands causes the intensive heating and structural changes in the amorphous alloy. These changes influence the magnetic properties of the amorphous precursor for the Finemet crystallization.
\end{abstract}

PACS numbers: 61.43.Dq, 62.20.Hg

\section{Introduction}

In recent years the range of available soft magnetic materials has been significantly increased by the development of nanocrystalline magnetic materials beginning with Yoshizawa et al. [1]. The most widely investigated Finemet alloy is $\mathrm{Fe}_{73.5} \mathrm{Nb}_{3} \mathrm{Cu}_{1} \mathrm{Si}_{13.5} \mathrm{~B}_{9}$ which is produced by rapid solidification and then annealed above the crystallization temperature to produce the nanocrystalline structure $[2,3]$. The ribbon form is one of disadvantages of the used preparation procedure.

Plasticity of these materials is significant for their practical use. The plastic deformation of metallic glasses is carried out via the shear band creation and the shear in these bands. It was shown that the catastrophic shear band creation is done under nearly adiabatic conditions. The stored elastic energy releases by local heating of the material in the thin layer of the shear band. At the final stage of deformation the manifestations of local heating are observed as dimples or needles at fracture surface of failed metallic glasses [4]. It was observed that the high amount of plastic deformation energy introduced by intensive milling leads to partial or full crystallization of amorphous alloys $[5,6]$.

\section{Experimental}

It is well known that during the crystallization of amorphous $\mathrm{Fe}_{73.5} \mathrm{Nb}_{3} \mathrm{Cu}_{1} \mathrm{Si}_{13.5} \mathrm{~B}_{9}$ alloys, the first crystallization is associated with the ferromagnetic $\mathrm{Fe}-\mathrm{Si} \alpha$ phase production. The influence of the structural changes on the crystallization was studied by means of thermal analysis equipment Setaram TGDTA92 adapted to Faraday-type balance. For moderating the structure of metallic glass the repeated impact by hammer was used. The stored deformation energy was semiquantitatively described as a time during which the hummer impactions were made $(30 \mathrm{~s}$ - def1, $10 \mathrm{~min}$ - def 2 and $30 \mathrm{~min}$ def3). At used frequency of hits (approximately $2 \mathrm{~s}^{-1}$ ) no heating of sample was observed. The length changes of Finemet type amorphous ribbons $\mathrm{Fe}_{73.5} \mathrm{Nb}_{3} \mathrm{Cu}_{1} \mathrm{Si}_{13.5} \mathrm{~B}_{9}$ with dimensions of $20 \times 1.3 \times 0.027 \mathrm{~mm}^{3}$ were measured under uniaxial tension of $2.5 \mathrm{MPa}$ during heating with the constant rate of $10 \mathrm{~K} / \mathrm{min}$ in flowing Ar using thermomechanical analyser Setaram TMA92 with the resolution of $10 \mathrm{~nm}$.

\section{Results and discussion}

The hammer impact on the amorphous ribbons cause the shear band creation visible as the linear steps on the free surface as can be seen in Fig. 1. Increase of stored deformation energy causes the increase of shear band density and more complicated distribution of the shear bands.

The thermomagnetic traces for the original as quenched and three different deformed states measured during heating at constant rate of $20 \mathrm{~K} / \mathrm{min}$ are shown in Fig. 2. The transition to the paramagnetic state in amorphous structure is observed for all deformation states. The Curie transition temperature in amorphous state (about $560 \mathrm{~K}$ ) is independent of the examined structural states. The different magnetic forces in the Faraday-type balance for samples with different structure at lower temperatures can be caused by the structural changes in shear bands and by the presence of the introduced stress field as well as by the different structural relaxation of amorphous structure [7]. The production of the ferromagnetic $\mathrm{Fe}-\mathrm{Si} \alpha$ phase above $780 \mathrm{~K}$ causes the increase of the magnetization. 


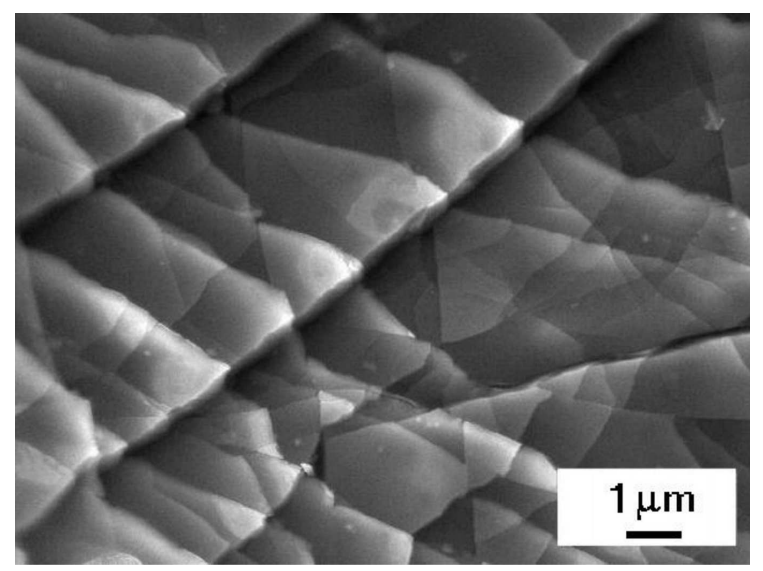

Fig. 1. The shear bands on the free surface of amorphous ribbon.

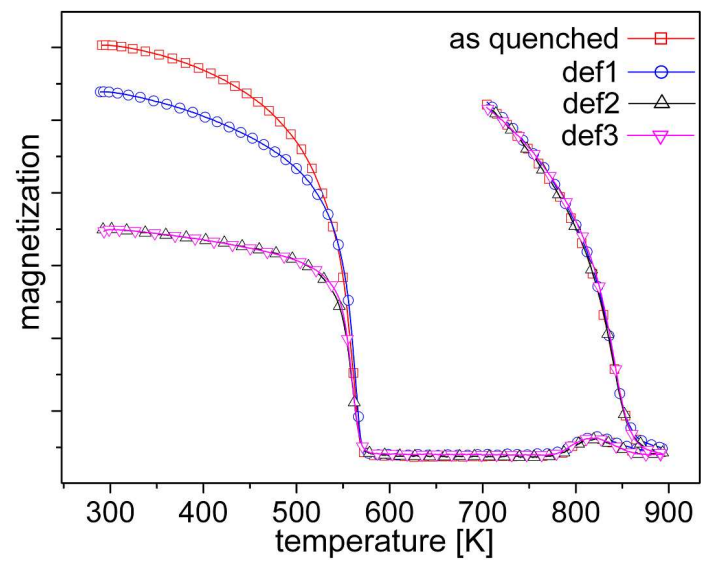

Fig. 2. The temperature dependences of the magnetization for the undeformed sample and for samples in different deformed states.

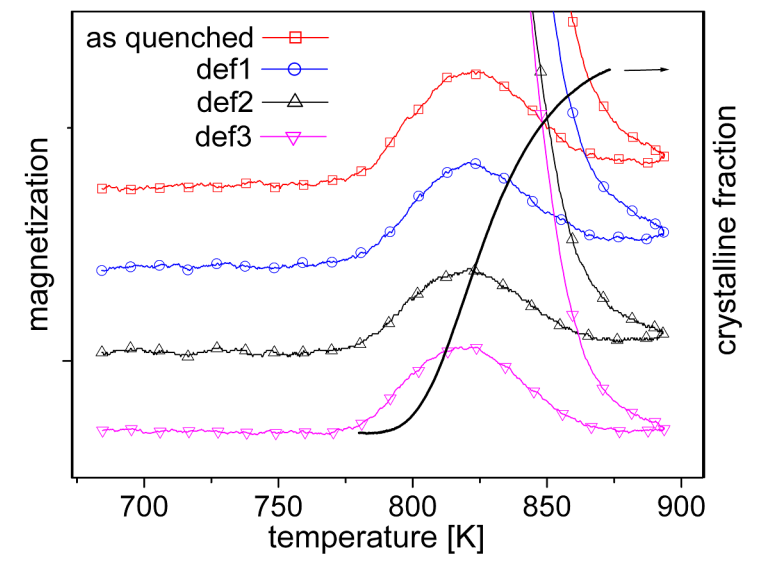

Fig. 3. The temperature dependences of the magnetization in the crystallization region. The temperature dependence of the crystalline fraction is attached.
The detail in Fig. 3 shows that no differences in crystalization kinetics of samples in different deformation state characterized by the thermomagnetic method were observed. In the figure, the portion of crystalline fraction determined by the dilatometric method is added for a comparison.

The increase of magnetization in the temperature range of $770-820 \mathrm{~K}$ is due to the increase of crystalline portion. Although during next temperature increase the crystallization continues, the magnetization decreases due to the approaching of the Curie transition of magnetic crystalline Fe-Si $\alpha$ phase. During following cooling, the transition to the magnetic state manifested by increase of the magnetic force is independent of the initial amorphous structural state.

The influence of structural relaxation on the magnetization of highly deformed sample at two subsequent heating is shown in Fig. 4. During first heating up to the temperature of $700 \mathrm{~K}$ the structural relaxation occurs. During the second run the magnetization seems to be similar as that for undeformed sample. So we can conclude that structural defects introduced by the deformation are annealed out during the first heating up to $700 \mathrm{~K}$ and therefore no significant influence of the accumulated plastic deformation on the crystallization process is observed.

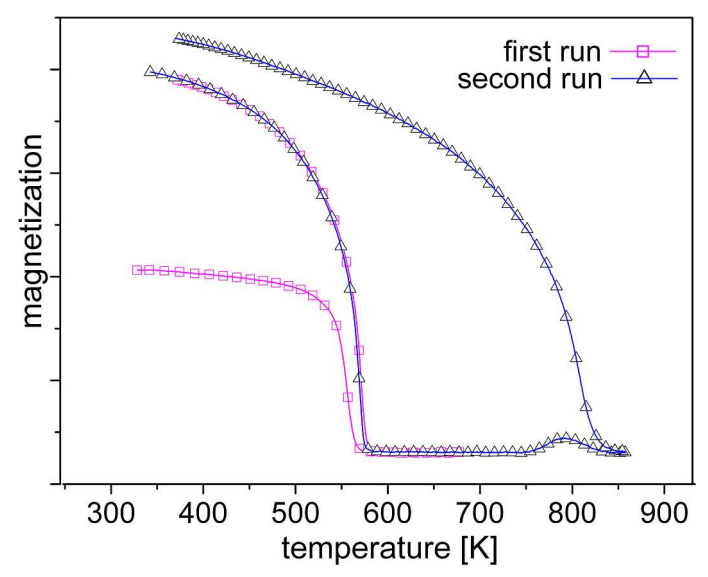

Fig. 4. The temperature dependences of the magnetization at two heating runs.

Due to the catastrophic condition during shear band generation the deformation energy is localized in a narrow band. In short time the heat dissipation leads to the rapid cooling of heated shear bands. The production of shear bands is connected with the saving of amorphous structure. On the other hand, the partial crystallization observed for samples after the intensive ball milling $[5,6]$ is possible due to much higher deformation work accumulated after long time milling.

\section{Conclusion}

We studied the influence of the plastic deformation via creation of shear bands on the crystallization of Finemet 
alloy. The thermomagnetic study has shown that even small deformation leads to a change in the magnetization of amorphous phase. During heating the structural relaxation occurs and the contribution of the modified structure inside shear bands vanishes and no differences in the crystallization products were observed.

\section{Acknowledgments}

This work was created by the implementation of the project No. 26220120021 provided by the European Regional Developments Fund. The authors are also grateful to the Grant Agency VEGA and the Centre of Excellence - Nanofluid of Slovak Academy of Sciences.

\section{References}

[1] Y. Yoshizawa, S. Oguma, K. Yamauchi, J. Appl. Phys. 64, 6044 (1988).

[2] G. Herzer, J. Magn. Magn. Mater. 157, 133 (1996).

[3] V. Ocelík, K. Csach, A. Kasardová, J. Miškuf, P. Švec, K. Krištiaková, I. Mat'ko, Scr. Mater. 35, 1301 (1996).

[4] V.Z. Bengus, E.D. Tabachnikova, S.E. Shumilin, Y.I. Golovin, M.V. Makarov, A.A. Shibkov, J. Miskuf, K. Csach, V. Ocelik, Int. J. Rapid Solid. 8, 21 (1993).

[5] R. Bhowmick, R. Raghavan, K. Chattopadhyay, U. Ramamurty, Acta Mater. 54, 4221 (2006).

[6] J. Bednarcik, E. Burkel, K. Saksl, P. Kollar, S. Roth, J. Appl. Phys. 100, 014903 (2006).

[7] K. Csach, V. Ocelík, J. Miškuf, V.Z. Bengus, P. Duhaj, IEEE Trans. Magn. 30, 496 (1994). 